\title{
PALPABLE VENOUS PULSATIONS IN A CASE OF TRANSPOSITION OF BOTH ARTERIAL TRUNKS AND COMPLETE HEART BLOCK
}

\author{
BY \\ J. D. AITCHISON, R. J. DUTHIE, AND J. S. YOUNG \\ From the Royal Infirmary Aberdeen and the Department of Pathology, University of Aberdeen
}

Received July 29, 1954

The case described is one of cyanotic congenital heart disease, with complete A-V block. Pulsations at the same rate as those of the atria, and at rather more than double the ventricular and radial pulse rates, could be easily felt above the clavicles and in the groins. These pulsations were so forcible that they were thought to be arterial in origin by a number of observers. We are of the opinion that they were venous pulsations, arising in the right atrium and reaching the femoral and jugular veins via the venæ cavæ.

\section{CASE REPORT}

The patient was 34 years old. Cyanosis had been noted when he was nine months and he had become breathless on slight exertion from the time he could walk. He had been well enough to follow various light occupations until 1944, when at the age of 27, he was admitted to hospital because of melæna. He was found then to have complete A-V block and cyanotic heart disease, thought to be pulmonary stenosis and ventricular septal defect.

Examination showed marked cyanosis, clubbing of the fingers, œdema of the legs, and ascites. The radial and posterior tibial arteries were beating regularly at 44 a minute. Pulsations at 103 a minute, which were irregular in force, were felt in both groins and above the clavicles. The apex beat was in the fifth intercostal space in the anterior axillary line. A systolic thrill was palpable over the whole præcordium. The first heart sound was replaced by a long, loud, harsh systolic murmur, best heard at the pulmonary area, but audible over the whole præcordium. The second heart sound could not be identified. Between the murmurs there were softer and more rapid sounds, thought to be due to atrial contractions. Some murmurs were louder than others, presumably because of atrial and ventricular contractions occurring close to one another. The blood pressure was 155/90. The urine contained albumin (12 parts Esbach). The hæmoglobin was 152 per cent and the red blood corpuscles 9 millions per cu. mm. Examination of the other systems showed nothing of note.

After the signs of congestive failure had cleared, the venous pressure in the right arm was $6 \mathrm{~cm}$. of saline above the manubrium sterni. Pulsations of the same rate and pattern were seen and felt over the jugular and femoral veins at the same rate as the $P$ waves. The left femoral artery and vein were exposed surgically. The artery was seen pulsating at 45 a minute, and the vein, almost as vigorously, at 100 a minute. The mean pressure in the femoral vein was $6 \mathrm{~cm}$. of saline above the manubrium sterni with the patient recumbent, and in the saphenous vein $5.5 \mathrm{~cm}$. The venous pulse pressure could not be measured because of the inertia of the saline manometer, but the vein was observed to bleed in spurts, like an artery. The venous pulsations were therefore of atrial origin, reaching the groins and neck via the venæ cavæ. The waves recorded from the groins varied manifestly in size, and tracings taken simultaneously from the right groin and from the cardiac apex showed that the largest waves in the femoral tracings occurred at about the same time as ventricular contractions, i.e. when the tricuspid valve was closed (Fig. 1, a3, a5, a8, and a10). They were, then, so called "cannon" waves. Either one or two waves occurred between each successive pair of cannon waves. Where two waves occurred (Fig. 1, a1 and a2, a6, and a7) the earlier of the two was always the smaller and this is explained by the atrium contracting early in ventricular diastole, when the ventricular pressure was lower and the tricuspid valve wider open than when the next atrial contraction 
occurred towards the end of ventricular diastole. The size of each wave can be related to the stage of the ventricular cycle at which it occurred, the waves increasing in size the later in ventricular diastole they appeared, the largest being during ventricular systole (Fig. 1, a3, a5, a8, and a10).

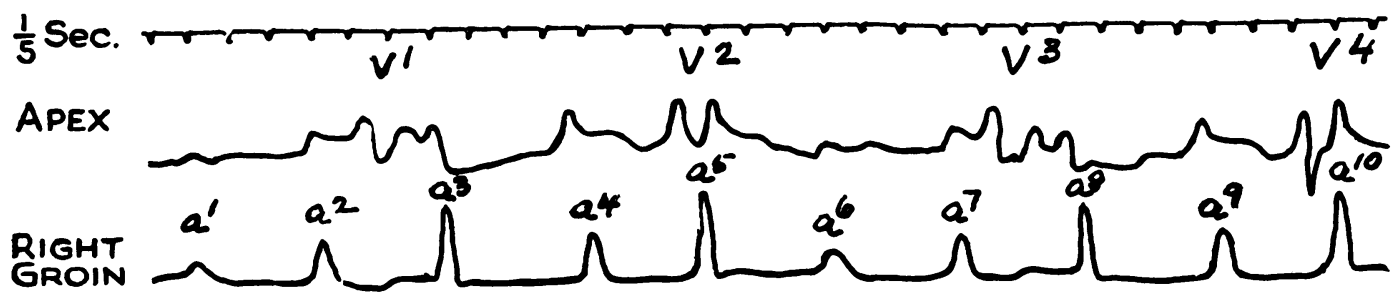

Fig. 1.-Polygraph tracings taken over cardiac apex and right groin (see text).

X-ray examination showed that the heart was markedly enlarged, particularly the right atrium and right ventricle. Electrocardiograms confirmed the presence of complete A-V block. Right axis deviation and tall R waves in leads aVR and V1 to V4 were clear evidence that the right ventricle was greatly hypertrophied.

The patient was treated along the usual lines for cardiac failure and recovered enough to be able to walk short distances. After several further episodes of congestive failure, he was admitted to hospital again some months later in an attack from which he did not recover.

\section{Summary of Post-mortem Findings}

Bilateral hydrothorax and extensive collapse of both lungs. Hydropericardium and ascites (500 ml.). Chronic venous congestion of viscera.

The Heart. The pericardial sac contained some $500 \mathrm{ml}$. of pale greenish transudate and irregular sclerotic patches were noted in the epicardium but, in other respects, the sac was normal. The anterior aspect of the heart in situ was trapezoid in shape and the aorta, springing from its upper left angle, arched upwards, backwards, and to the right: the front of the ascending portion of the arch was overlapped by the greatly enlarged auricle of the right atrium which concealed the pulmonary trunk behind it (Fig. 2). The main

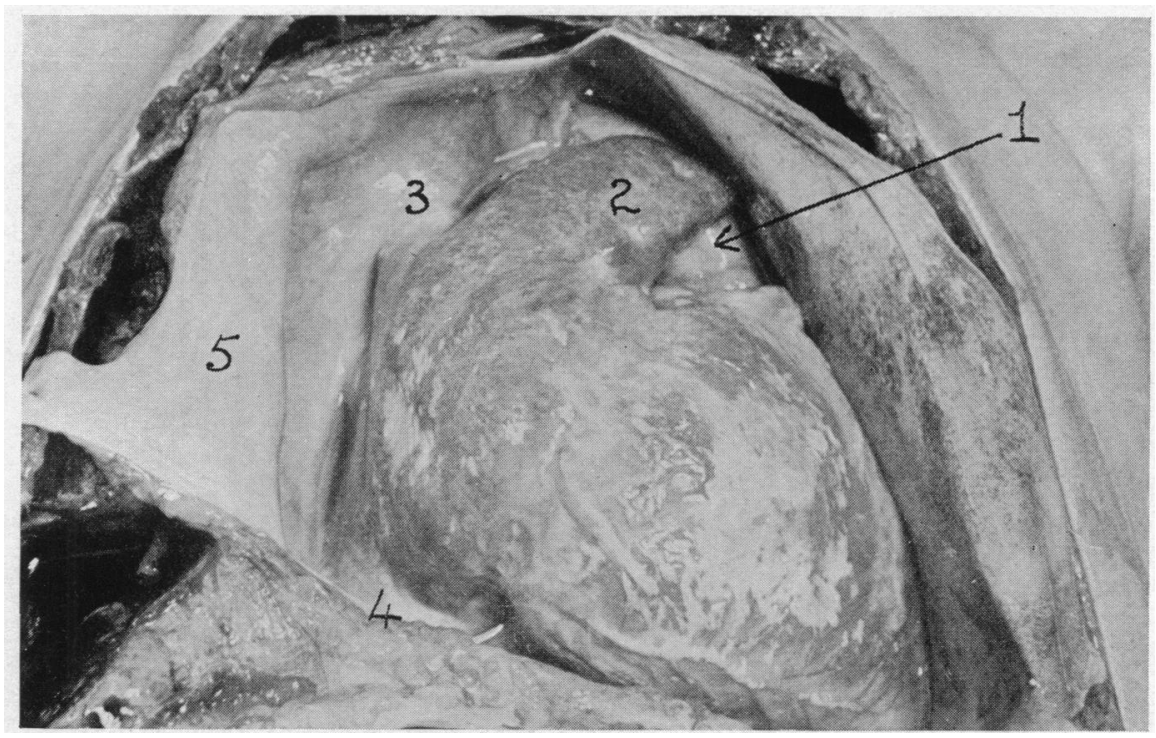

FIG. 2.-The heart in situ in the opened thorax. (1) Aorta. (2) Enlarged auricle of right atrium. (3) Superior vena cava. (4) Inferior vena cava. (5) Reflected parietal pericardium. 
branches of the aorta were normal in their origin and distribution and the ligamentum arteriosum was impervious. The several measurements recorded below were made on the formalin-fixed heart.

The ventricular portion of the heart was sub-divided into a large conical right-sided chamber and a small concave-convex left-sided chamber by an abnormal septum presenting an arched defect, $20 \mathrm{~mm}$. at the base and $10 \mathrm{~mm}$. high, in its upper and posterior part, through which the two chambers communicated. The left-sided chamber (Fig. 3), measuring $25 \mathrm{~mm}$. from base to apex, $25 \mathrm{~mm}$. from front to back, and $10 \mathrm{~mm}$.

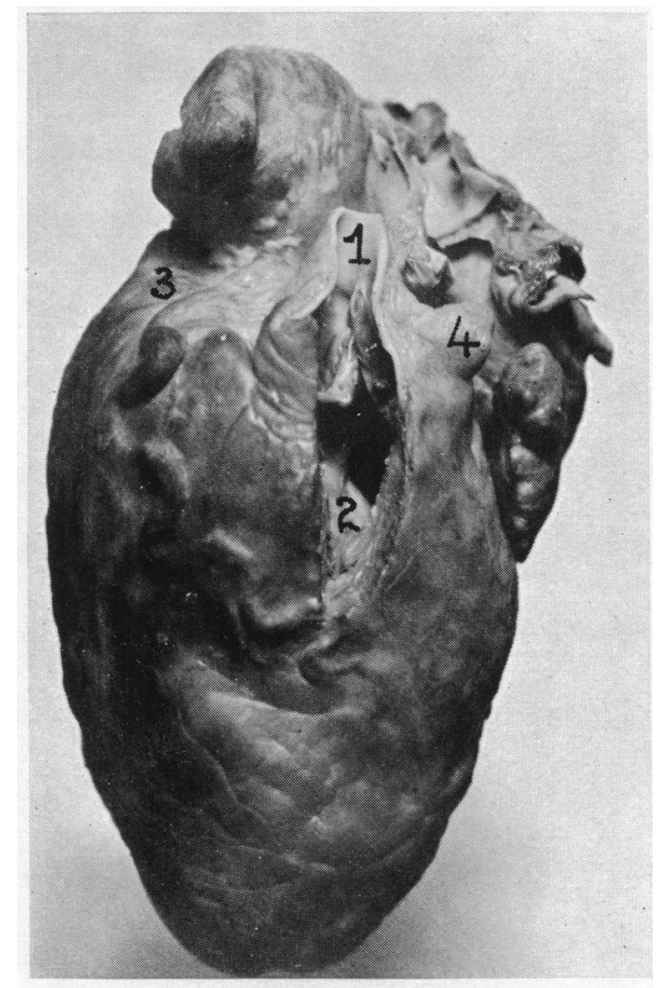

FIG. 3.-Left-sided ventricular chamber : outer wall excised. (1) Aorta. (2) Abnormal septum and base of arched defect. (3) "Anterior" and (4) "Posterior" coronary artery.

in maximum depth near the base, was situated almost exactly in the sagittal plane and gave origin from its base to the aorta; its wall had a maximum thickness of $11 \mathrm{~mm}$. The aortic valve (after restoration of an excised wedge) measured $65 \mathrm{~mm}$. in circumference (normal, $75 \mathrm{~mm}$. in fresh state) and possessed three well-formed semilunar cusps of nearly normal texture, one posterior and two antero-lateral. The rightsided chamber, measuring $90 \mathrm{~mm}$. in internal length from base to apex and $50 \mathrm{~mm}$. in diameter near its base, had a wall of $15 \mathrm{~mm}$. thickness. It was a composite chamber into which both A-V orifices led and from which the pulmonary artery sprang behind and to the right of the aorta (Fig. 4), in a narrow interval between the septal cusp of the right A-V valve and the upper limb of the abnormal septum. The channel of exit from the ventricular chamber into the pulmonary artery (deliberately avoiding the term " infundibulum ") measured only $30 \mathrm{~mm}$. in circumference; its wall was sclerosed by fibrous tissue, representing a pre-valvular stenosis; the circumference of the artery increased to $47 \mathrm{~mm}$. (normal, $72 \mathrm{~mm}$.) at the level of the valve which possessed only two cusps, namely a large anterior and a small left postero-lateral, united near their contiguous margins by a supplementary bridge of fibrous tissue. The right A-V orifice was guarded by a valve with three identifiable cusps, septal, posterior, and anterior, and its axis was directed from above, downwards, and to the left towards the lower limb of the abnormal septum. The left A-V orifice, situated behind and to the right of the tricuspid, was guarded by two cusps, an anterior and a posterior of nearly equal size, and its axis was directed from above, downwards, and to the right towards a pocket, formed by 


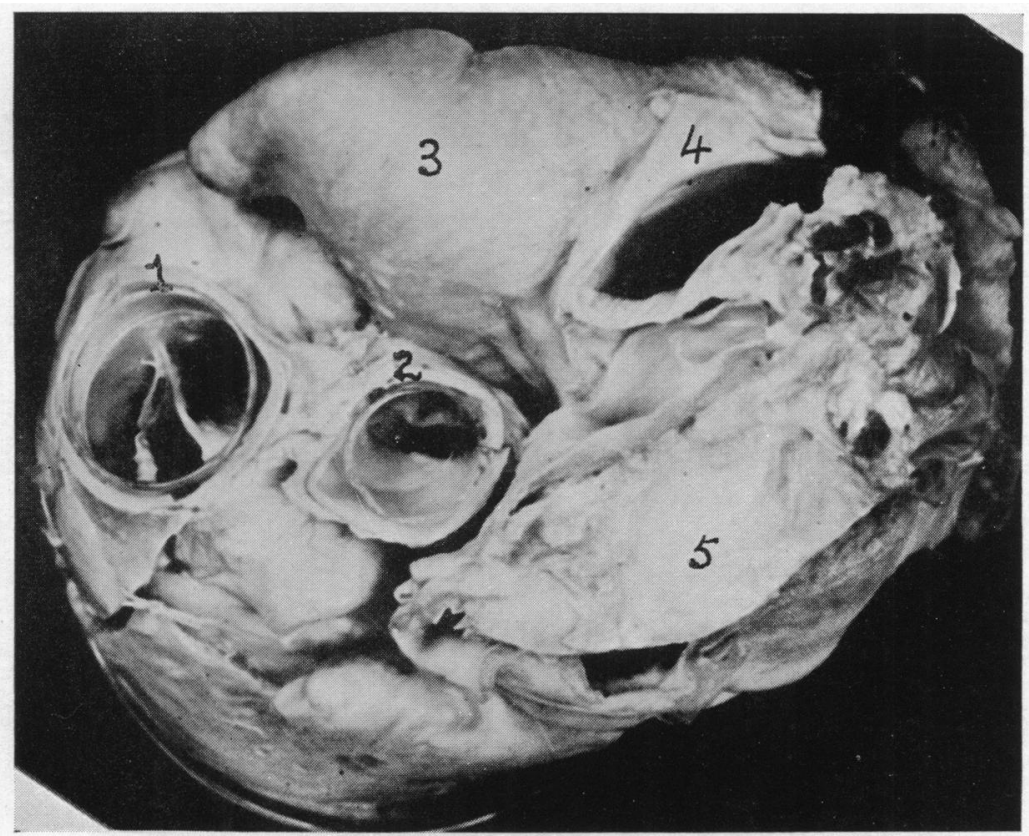

FIG. 4.-Base of heart, viewed from above and slightly behind. The reconstructed and partially collapsed aorta and pulmonary artery are distended with glass rings. (1) Aorta showing right and left anterior cusps. (2) Pulmonary artery showing part of anterior cusp only. (3) Enlarged auricle of right atrium with deep aortic groove on posterior surface near tip (displaced forwards for photographic purposes). (4) Superior vena cava. (5) Left atrium.

the bases of two papillary muscles on the outer (i.e. right lateral) wall of the chamber. The cusps of the bicuspid (mitral) valve were normal in texture but those constituting the tricuspid valve were sclerosed, especially the septal cusp which presented a rounded fibrous polyp, some $5 \mathrm{~mm}$. in diameter, on its atrial surface. The papillary muscles and chordæ tendineæ showed only one notable abnormality, evidenced by the attachment of a thick muscular bundle, derived from the coalescence of two papillary muscles, to the ventricular surface of the anterior cusp of the tricuspid valve. The apical part of the chamber presented prominent columnæ carneæ, mainly disposed in a longitudinal direction, and was crossed horizontally by one conspicuous muscular bundle representing a moderator band. The circumference of the right and left A-V orifices measured respectively $80 \mathrm{~mm}$. (normal, $120 \mathrm{~mm}$.) and $72 \mathrm{~mm}$. (normal, $100 \mathrm{~mm}$.).

The right atrium measured $100 \mathrm{~mm}$. transversely from its right lateral wall to the tip of its auricle and $50 \mathrm{~mm}$. in the vertical plane. Its wall was hypertrophied up to $3 \mathrm{~mm}$. in thickness, exclusive of the unusually prominent musculi pectinati, despite the considerable dilatation of its chamber. The orifices of the superior and inferior venæ cavæ were normal except that the Eustachian valve was not identifiable. The orifice of the coronary sinus was imperforate and the cardiac veins drained into a persistent left superior vena cava. The foramen ovale was patent as a slit-like aperture, $10 \mathrm{~mm}$. in length, guarded by a flap valve on the left surface of the inter-atrial septum. A broad groove on the surface of the posterior wall of the right auricle marked the site of contact with the ascending aorta. The left atrium was situated directly behind the right, slightly to the right of centre; it measured $45 \mathrm{~mm}$. in the transverse and $30 \mathrm{~mm}$. in the vertical plane. Its wall was slightly hypertrophied, up to $2.5 \mathrm{~mm}$. in thickness, and its chamber was dilated but much less than that of the right. The pulmonary veins entered the right and left upper angles of the left atrium in the normal situation.

The coronary arteries, springing one from the right anterior and another from the posterior sinus of Valsalva, had an anomalous distribution and were transposed as described by Spitzer; both were unusually large and tortuous and exhibited patches of atheroma.

Comment. It is not proposed to discuss here the arguments for and against Spitzer's phylogenetic theory of the transposition of the arterial trunks. It is sufficient to say that the heart described above is closely 
similar to his Case 9 (1923, pp. 243-253). Indeed it differs only in the respect that " detorsion of the bulb," in Spitzer's phrase, has proceeded still further to the extent that the " aortic chamber " has been carried from the right anterior to the left lateral aspect of the heart. Presumably as a result of this increased " detorsion," the conus of the right ventricle has been compressed, a pre-valvular stenosis of the pulmonary artery has developed, and the pulmonary valve has become bicusped while the aorta, identified by Spitzer as the homologue of the right (reptilian) aorta, receiving an increasing volume of blood through the defect in the abnormal septum, has undergone a corresponding enlargement and has retained three enlarged cusps. The " aortic chamber" is, in fact, a minor segment of a morphologically right ventricle, communicating through a defect in an abnormal septum with a major segment of the same which has coalesced with a morphologically left ventricle owing to the suppression of development of a normal interventricular septum. No clinical details about Spitzer's Case 9 are reported but he attained adult life like the present patient.

Analysis of the hæmodynamics of a structurally abnormal heart is always hazardous, especially in a fixed organ, but there are some notable findings in this instance which might be significant in the interpretation of the clinical manifestations:

(1) The deviation of the axes of the right and left A-V valves should have effected a partial separation of the venous and oxygenated blood and ensured that the blood entering the pulmonary artery was mainly venous.

(2) Having regard to $(a)$ the large capacity of the chamber of the composite ventricle, $(b)$ the rigidity of the small exit from it into the pulmonary artery, and $(c)$ the comparatively large aperture leading into the " aortic chamber," it is almost certain that the aorta was not only larger than normal but also, perhaps, abnormally distended during each ventricular systole. This proposition is supported by the appearances of the aorta in situ (Fig. 2). Therefore, the reduction in the measured circumference (from 75 to $65 \mathrm{~mm}$.) of the reconstituted aortic valve in the formalin-fixed specimen is probably misleading.

(3) The fibrous thickening of the cusps of the right A-V valve would suggest that there had been a moderate degree of stenosis, probably associated with incompetence, during life.

(4) The relatively great enlargement of the chamber of the right atrium and the greater hypertrophy of its wall compared with that of the left would suggest that occasionally at least, if not during every atrial systole, blood was expressed from the right atium into the left through the patent foramen ovale.

(5) The conspicuous groove upon the posterior surface of the greatly enlarged right auricle, where it impinged upon the ascending aorta, admits no reasonable doubt that the pulsation of the aorta was transmitted to the blood contained in the right atrium during every ventricular systole, whether that pulsation was recordable in the peripheral venous circulation or not.

\section{Discussion}

Pulse waves synchronous with atrial systole can be demonstrated in the jugular vein in normal subjects, the " a " wave of the jugular phlebogram. Except for the vestigial Eustachian valve, there are no valves between the venæ cavæ and the atrium. Muscular bands thought to close the venous orifices during atrial systole, have been described by Keith (1902). Authorities differ in their explanations of the mechanism of production of the normal "a "wave. Best and Taylor (1950) state that the jugular vein is in direct communication with the interior of the atrium and that changes in volume and pressure in the atrium are transmitted to the column of venous blood. According to Wiggers (1949) the venous channels remain patent and regurgitation of blood into the venæ cavæ is prevented (1) by the necessity of stopping the forward flow before the stream can be reversed, (2) by the pressure being lower in the ventricle than in the veins so that the atria tend to empty in the direction of least resistance, (3) by the peristaltic mode of contraction favouring emptying towards the ventricles, and (4) by the emptying of atria during early (ventricular) diastole so that they contain but a small quantity of blood when they contract.

Wright (1952) explains the "a" wave by a rise in pressure in the great veins, caused by stasis of the blood stream. He states that there is no regurgitation of blood from atrium to veins during atrial systole as the orifices are then closed by the sphincter-like action of sleeves of atrial muscle. Evidence in agreement with this latter view has been recorded by Hedman et al. (1953) by rapid angiocardiographic studies: they conclude that the caval orifices are normally closed during atrial systole. 
Clinically detectable pulsations in limb veins have been described in cases of relative and absolute tricuspid incompetence, sometimes with varicosity of the veins of the legs (Benson, 1836; Kerr and Warren, 1925; Clerc and Mourrut, 1931; Hallok and Clarke, 1941; and Sensenbach and Hutaff, 1943).

Unusually large atrial (giant "a") waves may be seen in the jugular venous pulse in severe pulmonary stenosis, pulmonary hypertension, and tricuspid stenosis (Wood, 1950). Visible and palpable presystolic waves were described by Dagnini (1894) in sphygmograms taken from the groins in a case of rheumatic heart disease; he thought that they were of atrial origin and transmitted to the femoral vein and that tricuspid stenosis was present in his case. Pezzi and Gasperini (1914) described similar waves in three cases of congenital heart disease, but these waves do not seem to have been palpable: pulmonary stenosis was present in two of the cases.

Waves at atrial rate are often visible in the jugular pulse in complete A-V block. Kerr and Warren (1925) mention a case in which these waves were seen in the veins of the arms. When the atrium contracts against the closed tricuspid valve the " a" waves are larger than usual and these "cannon" waves are described as abrupt, variable, and of high amplitude (Wood, 1950). In a case of A-V block, without any valvular lesion, Pezzi et al. (1920) felt feeble pulsations at atrial rate in the groins, and were able to record these pulsations in sphygmograms taken over the femoral vessels. Webster (1901), Mackenzie (1913), and other authors have described small undulations at atrial rate, between the ventricular waves on the radial arteriogram, in cases of heart block. Mackenzie thought that these waves were produced by left atrial systole causing pressure on the aortic valves and so on the arterial blood column. Hedman et al. (1953) in their angiocardiographic studies in a case of complete heart block found regurgitation of contrast medium from atrium into venæ cavæ when atrial and ventricular systoles coincided.

In the case described here, we consider that the contractions of the greatly hypertrophied right atrium overcame the normal mechanism for closing the caval orifices, causing regurgitation of blood into the venæ cavæ and so producing the remarkably vigorous pulsations in the veins of the groins. This would seem to be the mechanism whereby giant "a " waves in the jugular venous pulse are produced in conditions leading to marked hypertrophy of the chambers of the right heart. The fact that the largest of these pulsations in the femoral veins coincided with the ventricular pulsations, and so with closure of the tricuspid valve, indicates a similar causal mechanism for the "cannon" waves of heart block.

In our case the pulsations were unusually evident because of the combination of gross right atrial hypertrophy and complete A-V block. Pulsations of atrial origin may reach the femoral veins more frequently than is recognized. Their presence will be difficult to detect by ordinary clinical examination, except possibly when there is coexistent complete heart block.

\section{SUMMARY}

A case of mixed transposition of both arterial trunks, exemplifying Spitzer's Type IV, with complete atrio-ventricular block is described.

Pulsations at the same rate as the atrium were easily palpable in both groins. These pulsations were shown to be occurring in the femoral veins and the mechanism of their production is discussed.

We are indebted to Dr. Douglas Taylor for the polygraph tracing.

\section{REFERENCES}

Benson, C. (1836). Dublin J. Med. Chem. Sci., 8, 324. Best, C. H., and Taylor, N. B. (1950). Physiological Basis of Medical Practice, p. 223. Baillière, Tindall, and Cox,
London.

Clerc, A., and Mourrut, E. (1931). Bull. Mem. Soc. Méd. Hôp., Paris, 47, 285.

Dagnini (1894). Cited by Pezzi and Gasperini (1914).

Hallok, P., and Clarke, W. D. (1941). Amer. Heart J., $22,410$.

Hedman, C., Lind, J., and Wegelius, C. (1953). Brit. Heart J., 15, 143.

Keith, A. (1902). Proc. Anat. Soc. Great Britain and Ireland, p. 2. 
Kerr, W. J., and Warren, S. L. (1925). Arch. intern. Med., 36, 593.

Mackenzie, J. (1913). Diseases of the Heart. 3rd ed., p. 269. Oxford University Press, London.

Pezzi, C., Donzelot, L., and Yacoel, J. (1920). Arch. Mal. Coeur., 13, 97. and Gasperini, U. (1914). Arch. Mal. Coeur, 6, 594.

Sensenbach, C. W., and Hutaff, L. W. (1943). Amer. Heart J., 25, 539.

Spitzer, A. (1923). Virch. Arch. path. Anat. Phys., 243, 81-272.

Webster, A. (1901). Glasgow Hosp. Rep., 3, 413.

Wiggers, C. J. (1949). Physiology in Health and Disease. 5th ed., p. 583. Henry Kimpton, London. Wood, P. (1950). Brit. med. J., 2, 639.

(1950). Diseases of the Heart and Circulation, p. 122. Eyre and Spottiswoode, London.

Wright, S. (1952). Applied Physiology, p. 259. Oxford Med. Publications, London. 